\title{
Demonic Dreaming: Two Case Studies
}

\author{
Yong $\mathrm{Lu}^{1,2^{\star}}$ \\ ${ }^{1}$ Institute of Psychology, Faculty of Christian Philosophy, Cardinal Stefan Wyszyński University in Warsaw \\ ${ }^{2}$ Faculty of Psychology and Educational Sciences, KU Leuven (Katholieke Universiteit Leuven)
}

\begin{abstract}
The intriguing study of dreams related to mystical symbols has attracted not only such conventional fields as comparative religions and philosophy, but also psychoanalyses. In this report, first, the author briefly introduces, from the perspectives of Freud and Jung, the importance of energetic desire (libido), symbolism, and unconsciousness in interpreting dreams. Then, the author presents two case studies focusing on demonic dreams, which have been rarely investigated in scholarly research. The dreams are discussed in terms of their significance in the dreamers' experience and their implications for the use of dreams in psychoanalysis. The findings suggest that demonic symbols in dreaming could result unconsciously from dreamers' daily residues, fulfillment of will, or inferiority complex. The report discusses at the end Chinese folklore in interpreting demonic dreams.
\end{abstract}

Keywords: Daemons; Demons; Devils; Impactful dreams; Lucid dreams; Nightmares; Psychoanalysis; Satan; Significant dreams; Transcendent dreams.

"For in the multitude of dreams and many words there are also divers vanities: but fear thou God" (Eccl. 5:7).

\section{INTRODUCTION}

Dreaming is regarded as the inner eye to conjoin us with transcendent reality. For Freud and many others of his contemporaries, the value of dreams is an avenue into greater knowledge of potential consciousness. Through scrutinizing unconscious energy (or libido), especially forbidden sexual and aggressive ones according to the so-called laws of the unconscious, Freudians could access to what they called "drive factors," relating them to the analysis of dreams to the infantile experience, as well as to the ego operations and the transactions of the individual as manifest in the dream. In Freud's viewpoint, dreaming is

*Correspondence: luyong@student.uksw.edu.pl; yong.luastudent.kuleuven.be Yong Lu, 0314/N3, Waversebaan 220, 3001 Heverlee, Leuven, BELGIUM

Received: 05 January 2018 Accepted: 03 February 2018

\author{
Sleep and Hypnosis \\ Journal homepage: \\ www.sleepandhypnosis.org \\ ISSN: 2458-9101 (Online)
}

constellated around wish fulfillment and is from the "daemonic" power (1955, p. 609). Jung, however, maintains that dreaming contains more than wish fulfillment and they reveal an actually unconscious picture of the dreamer's personality (1949, p. 102). Jung accepts Freud's libidinal ideas that "the living body is ... a mental machine using mental conditions for the transformation of libido" (1928, p. 46) and that discharge of energy is caused by the state of inner conflict. However, Jung denies that the all powerfully sexual libido of Freud dominates "fantasies" (including dreams), one of the primary disagreements leading to their split. Instead, Jung proposes that different parts of the personality are charged with different loads of libido, which move progressively or regressively from one part to another and keep balance (Wolman, 1984, p. 269). Both of their orthodoxy contend that the contents of the unconscious are totally unrealizable except through the processes of dreaming, hypnosis, or psychoanalysis.

Jung and Freud create very different analytical psychologies. While Freud would have used an 
"association" approach to understand dreamers along with the retrospective theories of their identities and a tendency to unrestrained imaginations, Jung has employed a subjective "amplification" approach of exploring personal associations and a prospective/ objective "archetypal" approach of human individuation by means of his predilection for mythological and occult analogies. Jungian archetypal images (motifs; e.g., child hero, water, animus and anima, the mother archetype) are present in traditional beliefs, customs, folkways, legends, and rites, reflecting the people's collective memories (unconsciousness) of their ancestors (Wolman, 1984, pp. 275-280). As a result, Jung develops his enthusiastic interest in religion and mythology into his psychoanalytic ideas. In contrast, although born and raised in a Jewish family (cf., de Mendelssohn, 2013), Freud seems to see religion as the epitome of rational and philosophic enlightenment, denying the mystical side of oneself to a large extent. Instead, Freud recounts his lifelong predominant preoccupations with an uncommonly superstitious nature based on his professedly rationalistic scientism (Meissner, 1984, pp. 23-25). Such most striking preoccupation of Freud could be reflected on, for instance, his superstitiously numerological belief (e.g., Freud, 1955, pp. 456-459).

Both Freud and Jung all consider that visual images and symbols are of the important language of dreams, viewing symbols as "perhaps the most remarkable chapter of the theory of dreams" (Stafford-Clark, 1965, p. 82) and "the best possible formulation for still unknown or unconscious facts" (Jung, 1970, p. 540). The understanding of the meaning of a symbolic dream is, then, inextricably tied to the dreamer's past memories, experiences, daily life, or physical stimuli, which are comprised of the dreamer's consciousness, but stem from unconscious sources. However, their discrimination on symbolism of dreams lies in that the stereotype of the Freud's psychoanalytic theories specifies some signs and symbols certain specific meanings that are inclined to be related to sexual material and erotic wishes (e.g., a pillar as standing for a penis, a house for a womb), whereas Jung regards symbols as "properly speaking, a highly objective, natural product of the psyche ... withdrawn from our arbitrary will" (1963, p. 131). However, Forrer (2014) argued that Jung was wrong in rejecting Freud's sexual analysis; in fact, it proves to be the most reliable basis for a truly scientific verification of the meaning of a dream. More importantly, what separates Jung's psychoanalysis markedly from Freud's is that Jung sees dreaming as a parable, emphasizing the crucial determinant of action (plot) against Freud's heavy reliance on these fixed symbols, which Jung criticizes heavily (Jones, 1968). In light of this it is important to realize that Freud is caught out in going against the plot of the dream whose ultimate meaning he intends to fabricate instead of being guided by the plot, while Jung sees only few symbols as relatively fixed and that such symbols need amplification in order to be of interpretative value (K. Forrer, personal communication, January 4, 2018).

It is also important to emphasize two types of impactful dreams. Transcendent dreams contain high levels of intradream self-reflectiveness (open and sustained attention to personal thoughts, feelings, and activities), referring to ecstatic dreams concerned with magical accomplishment (Busink \& Kuiken, 1996; Kuiken, 1999). Significant dreams, as on-going living residents of a dreamer's psychological life, refer to influential dreams that significantly affect the dominant emotions and psychological faith of the dreamer's afterthought, viewed in the perspective of Jungian mytho-archetypal analysis (Knudson, 2003). Jung also asserts that significant dreams "are often remembered for a lifetime" and moreover "prove to be the richest jewel in the treasure-house of psychic experience" (1974, p. 76).

To the best of the author's knowledge, the discussion of demon attack dreams has been, on the one hand, scarecely investigated in previously psychoanalytical research studies, as evidenced by very limited instances from a search on Google Scholar and in academic databases. On the other hand, this dark side theme of dreams has not also been discussed much in public in view of the fact that it has either not usually happening or has been reluctant to be disclosed by these dreamers in light of the magnitude of dream reports, albeit calls for some explanations. Among the limited studies, van Eeden (1913) recorded his one lucid dream, in which he "was 
suddenly surrounded by many demons" and lost his selfcontrol, but eventually "threatened them with it [a whip]" (p. 11). Then the demons sneaked away. His selfinterpretation criticized putting all of the dream's symbols down to the unconscious; instead, he regarded the dream as of the uncanny, ordinary sort. Besides, Jacobi (1972) described two explanations of biological characteristics of monster or apparition dreams: one is due to purely physical phenomena (e.g., the feverish delirium, the pressure of bedclothes; cf., Bearden, 1994), and another is the belief in "devil spirits," as evidenced by dreaming ghost legends in China (e.g., Pu, 1916), Japan (e.g., Hori, 2005), and Europe (e.g., Amelang, 2012; Krappe, 1921). Nevertheless, little is known of dream life in which the devil and the demonic played a role.

The demonic dream is comparable but qualitatively distinct from the other disturbing dreams such as anxiety dreams (frightening dreams concerned with threats to physical well-being; cf., Busink \& Kuiken, 1996), bad (scary) dreams (frightening dreams concerned with nonawakening from sleep; cf., Fireman, Levin \& Pope, 2014), nightmares, or night terror (a purely emotional experience which takes place when the dreamer awakens from sleep). Take the nightmare for example, its generally accepted definition is a very disturbing dream that awakens the sleeper in fright (Hartmann, 1999; Zadra, Pilon \& Donderi, 2006) in contrast to demonic dreams which may incite horrors by the demon but may do not awaken the sleeper. Ernest Jones in his classic work, On the Nightmare, argued that nightmares as demonic dreams "originate in early mental conflicts relating to the parents --- notably repressed death wishes and guilt over incestuous impulses, in the primordial struggles between love and hate" (1931b, p. 364). Both types of dreams should share many clinical characteristics such as arising extendedly dysphoric emotions (e.g., anxiety, distress, fear, sense of guilt), in that they both seem to have similar inheritance patterns. Moreover, although demonic dreams are rarely occurring psychophysiological phenomena, if recurring and interfering with sleep, or excessively occupying subsequent waking thoughts, they may like nightmares, leading to psychiatric symptoms (e.g., traumas; Lansky \& Bley, 1995) or even suidcidal ideation.
The following two case studies detail the author's work using psychoanalysis in the instances of the author himself and his female friend, of which permission to use the latter's dream recounted as the second case here was obtained from her. Although the name of her is not real, the other information is accurate.

\section{TWO CASE REPORTS}

\section{The author's own dream}

This was the author's own dream which occurred during the night of September 15th, 2006, three months' later after he was baptized as a Christian. During that time, he was a graduate student and an infrequent dreamer (two lucid dreams per month on average), albeit a good dream recaller.

I and my youngest uncle came together at his residence, which is a small, single-room flat. $\mathrm{He}$ looked like very depressed. After my inquiry about the reason of his sadness, he told me that one of his friends had recently been tortured every night by a demon. While when he was anxious about this, I volunteered trying to cast out the devil because I am a Christian and have confidence to drive out the demon in the name of Jesus Christ. So we came together to the residence of his friend's flat, which is located inside of a long tube-shaped building. When I had just entered into the room of that flat, I saw that some people outside the corridor were in a panic and were running, and then a demon in black color and ball shape entered into the room. I was right away declaring in the name of Jesus Christ of Nazareth: "Satan, recoup!" After that, the demon was driven away. Then a lot of people were surprised that I had such authority, but I realized that the power came not from me, but from Jesus Christ. I gave the glory to the Heavenly Father afterwards.

According to Freud's most famous scientific book, The Interpretation of Dreams, dreams are likely to contain hidden thoughts and links to earlier experiences. On the day before this dream, the author read Martin Buber's 
book Two Types of Faith, in which the Gospel narrative of the healing of a boy possessed by a demon (Matt. 17:1421; see also Mk. 4:14-29) was elucidated (Buber, 1951, pp. 17, 20). This probably is the clue for the dream, simply a metaphor for the authority given by Jesus to $\mathrm{His}$ believers to cast out the demon (cf., Mt. 17:19-20; Mk. $4: 15,9: 28-29,16: 17$; Lk. 10:19), as well as for the forgiveness of sins by God by being baptized as a Christian (cf., Mt. 28:19-20; Mk. 16:16; Jn. 3:5). The contents of Buber's book have been hidden in the subconscious of the author before the dream happened.

The author had not in fact assured his Christian identity before this dream, since he had been concerned in the formality of his baptismal ritual, which was carried out in an underground home church (a flat) instead of the institutional church, where a layperson (a colleague student) baptized the author by simply dripping a few drops of water on the author's forehead instead of by dipping the author into a baptismal font (the English word baptize is derived from the Greek baptizō, literally meaning "to bury," "to dip," or "to immerse" in a liquid). After this dream, the author has deeply believed that God had already adopted him as a Christian, thereby ushering him into a certain belief that his informal, simple baptism is also admitted by Christ. As such, not only he believes the negation of the triple differentiations of Galatians 3:28a (neither Jew nor Greek, neither slave nor free, and neither male nor female), but also did he start to accept that there is neither informal nor formal baptism, "for you are all one in Christ Jesus" (Gal. 3:28b; cf., 1 Cor. 12:12-13). These ritual divergences that persisted in their tension with one another in the author's libido (i.e., an ego drive from the Freudian perspective) have been released after the dream. After conquering the demon (a magic performance), the author feels thoroughly joyful in spirits, which is accordant with the findings that transcendent dreams are associated with an ecstatic sense of spiritual release (e.g., Kuiken, Lee, Eng \& Singh, 2006; Lee \& Kuiken, 2015), and that dreams can provide spiritual inspiration (e.g., Schredl, Stumbrys \& Erlacher, 2016). In this regard, this dream is a truly significant, "big" dream, continuing to influence the author's on-going experience.
More plausibly, this dream is perhaps contradictory to Freud's purely physiological explanation of demonic dreams, which contends Aristotle who denies God or gods as the origin of and a divine character of dreams; instead, Aristotle declares that dreams are of a "daemonic" nature, an analogy paralleling in the human nature in contrast to supernatural (divine) manifestations (Freud, 1955, pp. 36-37). However, from the biblical point of view, "your old men shall dream dreams, and your young men shall see visions," the prophet Joel says (2:28). God has already spoken through dreams to the various Israelite forefathers (e.g., Gen. 15:12-13, 28:10-15, 37:5-9, 46:2-4), prophets (e.g., Dan. 2), and saints (e.g., Mt. 1:20-22; Acts. 16:9-10), thereby "speak[ing] in their ears and terrify[ing] them with warnings" (Job 33:16; for a hermeneutical review on the biblical dreams, see Lu, 2016). Bulkeley $(1994,1995,2000)$ also argued that at least some dreams present a true revelation of the divine.

Further, according to Freud and Jung, dreams are such attempts to resolve anxieties or conflicts during the waking state, representing a venue to weaken witting repression in the dreamers' memories. Before this dream, some doubt (e.g., the validation of his baptism, forgiveness of sins by God) has been cast in the author's memory upon his identity in front of God, which took his anxiety from him. The happening of this dream was an attempt to release the author's inner conflict on this matter, which is also in accordance with the finding that dreaming may help to solve personal problems of waking life (e.g., Schredl, 2000). The author's quest for the redemption of sinfulness should be related to his attentive wish and desire, in which the sense (consciousness) of guilt plays a prominent role. The sense of guilt is actually of fundamental importance in understanding the development of Freud's psychoanalytic work on the omnipresent tension between repressed desires and passions via, for instance, the Oedipus complex, the story of Oedipus' quest for the cause of Thebe's suffering (cf., Westerink, 2009).

\section{A female's dream}

In a conversation with Kong Dan, a female friend of the author, a Buddhist, and a graduate student in her middle twenties, she told in detail a dream that happened to her. 
The dream took place in an open-air courtyard, and in the dream, I was with a man who dressed up in Chinese traditional costume with his hair worn in a bun on the top of his head. Furthermore, the dream occurred when I firstly did not want the man to enter my courtyard. However, [later Kong Dan corrected in the conversation that] I actually wanted, but hesitated because I did not expect the man to see my embarrassment. Nevertheless, I and the man entered the courtyard eventually. We sat on two short stone benches, separated by a stone table in our middle. Meanwhile there was a little devil hidden under the table who started to threaten me with pushing me into a nearby pit. After that, I was really forced to enter and lie down in the pit, as if I was about to be buried.

Dream works involve condensation, displacement, and the translation of thoughts into visual images and symbols (Kaufmann, 1980). Psychoanalysis views one of the reasons that the manifestation of demons in dreams happens as projection of the sexual trend of the unconscious. More specifically, Freud decodes a great many of symbols in dreams in line with the male and female genitals, which "can be represented by an upright stick or a pillar, and so on" and "hollow objects, such as chests, cases, boxes, etc.," respectively (1955, pp. 247, 371). Besides, Jones (1931a) argued that a nightmare usually involves a psycho-sexual repression based on a violently psychical complex, representing "the normal sex act, and that in a characteristically feminine manner: ... the eventual genital secretion, etc.," holding that "'violently repressed desires' can be satisfied in this way: for example, ... sentiments of fear prevail over the sensation of lust," and reflecting "the normal process of coition" (quoted in Jacobi, 1972, p. 41).

In this dream, from Freud's viewpoint, the involved imagery may metaphorically point to a sexual theme: the courtyard could symbolize female genitals, and the man's coiled hair is obviously within the meaning of male genitals. While grounded in the tenet of Jung's psychology that archetypal motifs represent the heredity of culturally inherited patterns, Kong Dan's archetypes are expressed by such symbols as the Chinese traditional costume and bun-shape hairstyle. Kong Dan intended to let the man into her own courtyard, which could mean that she admitted this "incubus" and desired to have sexual relations. This sexuality-based speculation has been also evidenced by the actual life situation of Kong Dan, with whom the author contacted afterwards but was advised by a third person (the late spiritual leader of the author, Mr. Andrew Leong) that she intended to dating the author. Nevertheless, whether due to her own physical imperfections or lack of self-confidence (she was not good looking), she developed a kind of inferiority complex, in that in her conversation with the author, she expressed explicitly that she did not expect the man to see her embarrassment, as if she had expected herself to be disgraced before the man went into the courtyard.

As intrinsic as Kong Dan's wish fulfillment (i.e., the sexual desire), the process of her dream construction also involved resistance, which was impelled by her unwanted wishes (e.g., the lack of confidence), ideas, and feelings (e.g., the embarrassment), forcing themselves into the conscious during her dream (cf., Gillman, 1987). Her compromise (accepting the man into her yard) could reflect the unawareness of her conflictual elements stimulated the formation of the dream, resulting in a resistance. While from the Freudian framework's perspective, her psychological hesitation probably resulted from the conflict of the power of her evil desires (libido) with the lack of confidentiality on herself, and her circumspection could be also related to the circumstances of the sexual symbols in the dream. Jones (1951) also stated that such anxiety dream is due not to somatic sources from within, or demons from without, but erotic, incestuous wishes also from within, but from within the mental structures of the person herself. However, Jung heavily criticizes Freudians' drive theory and their distinction between ego derives and sexual drives. Instead, from the Jungian viewpoint, Kong Dan's libido is only primally undifferentiated life energy pursuing sensual pleasure or superiority, is equal to Schopenhauer's insatiable will, and should be desexualized (Jung, 1991).

Although assuming that Kong Dan overcame the depression of sexual instincts by inviting the man into the 
courtyard, she still could not get rid of the interference of her inferiority. Her low self-esteem was found and exposed her defects, that is, her being buried, although by force. According to St. Thomas Aquinas, demons could exert a greatly occult, albeit not miraculous effect over human, although only God had the power to produce miracles --- that is, to cause events beyond the ordinary course of nature (De Malo, 16.9; cf., Davies \& Regan, 2001). The little devil in this dream appeared itself in a virtually embodied form, imposing a powerful illusion in Kong Dan in order to tempt her into the pitfall. However, from the perspective of the Freudian school, the devil in this dream could symbolize the power of her inferiority complex, which eventually conquered her libidinal energy.

\section{CONCLUSIONS}

In its long history, the dream has often been treated not merely as an internally stimulated phenomenon, but also as possible means of divine communication. More specifically, tracing back to the medieval tradition, dreams in the diabolical world were regarded as arising from the similar psychic conditions as these at the root of contemporary dream theories to some extent akin to diseases (e.g., epidemics), neurological disorders (e.g., epilepsy), and extremely bad emotions (e.g., madness, apoplexies). In contrast to this the foremost Freudian and Jungian schools reach back to this old tradition of "explanations" on demon etiology, by substituting a seemingly new "psychological" formula for the antique conception of disturbing dreams. Furthermore, the causes of dreams are explained by psychoanalytical psychology as, for example, results of socially tabooed desire (e.g., Freud, 1955), wish-fulfillments (e.g., Freud, 1955; Solms \& Moorcroft, 1998), expressions of the higher self and the unconscious (e.g., Jung, 1963), the precursors of presleep mindfulness (Forrer, 2014; Lee \& Kuiken, 2015), and the source of our inspiration and motivation (e.g., Forrer, 2017). However, modern physiologists and neuropsychologists criticized Freud's work for being suffered from three fatally scientific defects: an absence of relevant brain science which Freud was aware of that, insufficiently, narrowly focused data, and attributional sexual desire (e.g., Hobson, 2002).

From an anthropological point of view, cultural factors may also play an important role in the process of dream formation, determining the construction of manifest contents of dreams. Psychosocial functions and folk styles that are prevalent in a culture should be also applied to dream interpretations (Cox-Miller, 1998; Freud \& Oppenheim, 1958; Hori, 2005; Kukharenko, 2017; Lu, 2016; Lv, 2012; Shushan, 2006; Walden \& Poch, 1998; Yin, $\mathrm{Li}, \&$ Shen, 2015). Take Chinese culture for example, dreaming was thought as the sights of the night-wandering soul, as stated in The Readings of the Tai-ping Era (Tai-ping Yu-lan 太平御覽, vol. 397), "The dream is of the symbol, and is the movement of the spirit and essence; the soul flees away from the dreamer, and gods move back and forth"(“夢者象也,精氣動也；魂魄離身，神來往也，" trans. mine). Besides, according to the folk dream interpretation legends, (1) dreaming attacking the demon indicates a good fortune, hinting that the dreamer could avoid a disaster through a positive preparation by oneself (Du, 1965), (2) dreaming the demon with beard indicates prolonging life, (3) dreaming the demon covered with cloth companied by the dreamer's modesty and avoidance of desire indicates a good fortune, (4) dreaming talking with the demon indicates a rich life, and (5) dreaming a mass of demons dismissed indicates a wealthy life and a good fortune (Zheng \& Yang, 1995, pp. 166-167). It is also noteworthy that in The Great Treatise (Ta Chuan 大傳) of The Book of Changes (I Ching 易經), it is said, "Therefore good fortune and misfortune are the images of gain and loss" (part I, chap. II, 3), manifesting that the trend of an action which is in harmony with the laws of the universe leads to attainment of the desired goal, as expressed in the appended phrase "Good fortune," whereas that the trend which is opposite in words and acts to the laws of the universe leads to loss, as indicated by the judgment "Misfortune" (Wilhelm, 1967, pp. 288-289). Thus, they appear only as a result of conduct of a corresponding kind. Nevertheless, dream interpretation should use common sense rather than simply relying upon dream handbooks and that dream interpretation proceeds more often by "atomization," which refers to the interpreter's 
method of isolating a dream's variously visual elements, assigning each its meaning.

In summary, the aim of this paper has been to analyze the meaning and function of two possibly impactful cases of dreams containing demonic imageries from a Freudian and Jungian psychoanalytical perspective involving libido, infantile sexual urges, symbols, the sense of guilty, and so on. With the two demonic dreams, this paper may have merit as a pilot study intended to propose a methodology for further research. The two dreams retrieve the day residues, will, and the unconscious of the dreamers and furthermore excavate their conscious desires. Since there have been by far only very limited research studies on demonic dreams, the current paper represents the simpler contemporary psychoanalyses of the two dreams with regard to a restricted attempt to compare them based on contents with any norms and classifications of "impactful" dreams containing demonic imagery, therefore presenting the two dreams as differing or similar in any way from the continuum of fairly "normal" dream activity. It is also admitted that it is uncertain how "unique" these two dreams are, since although containing uniquely demonic

\section{References}

Amelang, J. S. (2012). Sleeping with the enemy: The devil in dreams in early modern Spain. American Imago, 69(3), 319352.

Bearden, C. (1994). The nightmare: Biological and psychological origins. Dreaming, 4(2), 139-152.

Buber, M. (1951). Two Types of Faith. New York, NY: MacMillan.

Bulkeley, K. (1994). The Wilderness of Dreams: Exploring the Religious Meanings of Dreams in Modern Western Contexts. Albany, NY: SUNY Press.

Bulkeley, K. (1995). Spiritual Dreaming: A Cross Cultural and Historical Journey. Mahwah, NJ: Paulist Press.

Bulkeley, K. (2000). Transforming Dreams: Learning Spritual Lessons from the Dreams You Never Forget. NY: Wiley.

Busink, R., \& Kuiken, D. (1996). Identifying types of impactful dreams: A replication. Dreaming, 6(2), 97-119.

Cox-Miller, P. (1998). Dreams in Late Antiquity: Studies in the Imagination of a Culture, 2nd (Ed.). Princeton, NJ: Princeton University Press.

Davies, B., \& Regan, R. T. (2001). The De Malo of Thomas Aquinas. New York, NY: Oxford University Press.

de Mendelssohn, F. (2013). The Jewish tradition in Sigmund Freud's work. In W. Müller-Funk, I. Scholz-Strasser, and H. Westerink (Eds.), Psychoanalysis, Monotheism, and Morality: Symposia of the Sigmund Freud Museum 2009-2011 (pp. 3147). Leuven: Leuven University Press. imagery, the two case studies might be not so unique but simply metaphoric pictures of what were taking place in the dreamers' daily lives and the unconscious.

Acknowledgements: I thank Revd Prof. Dr. Tomasz Stępień at Faculty of Theology, Cardinal Stefan Wyszyński University in Warsaw for his teachings of the lecture "Angelology and Demonology of St. Thomas Aquinas" and his comments on an earlier version of this paper, thank Kurt Forrer for helpful written comments and criticisms on the content herein, and thank my doctorate supervisor, Prof. Dr. Marek Nieznański, for his encouragement. Otherwise indicated, the views expressed herein, however, are mine alone.

Conflict of interest: The author declares no conflict of interest.

Informed consent: Informed consent was obtained from all the participants (i.e., the author himself and Kong Dan in the second case study) included in the study.

Funding: The author declares that the current study was not financially supported by any institution or organization.
Du, Y. F. (1965). Modern Complete Collection of Chou Kung Dream Interpretation. Shaanxi: Shaanxi Normal University Press (in Chinese).

van Eeden, F. (1913). A study of dreams. In Proceedings of the Society for Psychical Research, Vol. 26, (pp. 1-12).

Fireman, G. D., Levin, R., \& Pope, A. W. (2014). Narrative qualities of bad dreams and nightmares. Dreaming, 24(2), 112-124.

Forrer, K. (2014). "To test or not to test; that is the question.": Is there a way of verifying the validity of the interpretation of our dreams? International Journal of Dream Research, 7(1), 153169.

Forrer, K. (2017). The dream as posthypnotic command. Sleep and Hypnosis, 19(4), 83-88.

Freud, S. (1955). The Interpretation of Dreams. J. Strachey (Ed.). New York, NY: Basic Books.

Freud, S., \& Oppenheim, D. E. (1958). Dreams in Folklore. New York, NY: International Universities Press.

Gillman, R. D. (1987). Dreams as resistance. In A. Rothstein (Ed.), The Interpretations of Dreams in Clinical Work (pp. 27-36). Connecticut: International Universities Press.

Hartmann, E. (1999). The nightmare is the most useful dream. Sleep and Hypnosis, 1(4), 199-203.

Hobson, J. A. (2002). Dreaming: An Introduction to the Science of Sleep. Oxford: Oxford University Press. 
Hori, T. (2005). Cultural note on dreaming and dream study in the future: Release from nightmare and development of dream control technique. Sleep and Biological Rhythms, 3(2), 49-55.

Jacobi, J. (1972). Dream Demons. In Sounding in Satanism (pp. 36-45). London and Oxford: Mowbrays.

Jones, E. (1931a). Nightmare, Witches, and Devils. New York, NY: W. W. Norton.

Jones, E. (1931b). On the Nightmare. London: Hogarth.

Jones, E. (1951). Beliefs concerning the nightmare. In Essays in Applied Psychoanalysis, Vol. 2 (pp. 110-113). London: Hograth Press and Institute of Psychoanalysis.

Jones, E. (1968). The Life and Work of Sigmund Freud (The Last Phase 1919-1939), Vol. 3. New York, NY: Basic Books.

Jung, C. G. (1928). Contributions to Analytic Psychology. London: Routledge and Kegan Paul.

Jung, C. G. (1949). In The Collective Works of C. G. Jung, Vol. 11.

Jung, C. G. (1963). Memories, Dreams, Reflections. New York, NY: Pantheon.

Jung, C. G. (1970). The undiscovered self. In The Collected Work of C. G. Jung, Vol. 10. Princeton: Princeton University Press (Original work published 1963).

Jung, C. G. (1974). Dreams. R. F. C. Hull (Ed. \& Trans.). Princeton: Princeton University Press.

Jung, C. G. (1991). Psychology of the Unconscious. A Study of the Transformations and Symbolisms of the Libido. A Contribution to the History of Evolution of Thought. Princeton: Princeton University Press (Original work published 1916).

Kaufmann, W. A. (1980). Discovering the Mind: Freud versus Adler and Jung. New York, NY: McGraw-Hill.

Knudson, R. M. (2003). The significant dream as emblem of uniqueness: The fertilizer does not explain the flower. Dreaming, 13(3), 121-134.

Krappe, A. H. (1921). The dreams of Charlemagne in the chanson de Roland. Papers of the Modern Literature Association, 36(2), 134-141.

Kuiken, D. (1999). An enriched conception of dream metaphor. Sleep and Hypnosis, 1(2), 112-121.

Kuiken, D., Lee, M. N., Eng, T. C., \& Singh, T. (2006). The influence of impactful dreams on self-perceptual depth and spiritual transformation. Dreaming, 16(4), 258-279.

Kukharenko, S. (2017). The difference of modern lucid dreamers. International Journal of Dream Research, 10(1), 10-14.
Lansky. M., \& Bley, C. (1995). Posttraumatic nightmares: Psychodynamic explorations. Hillsdale, Michigan: Analytic Press.

Lee, M. N., \& Kuiken, D. (2015). Continuity of reflective awareness across waking and dreaming states. Dreaming, 25(2), 141-159.

Lu, Y. (2016). A theological, ancient Hellenistic, and psychological look at the dreams of Pharaoh's chief cupbearer and chief baker (Gen. 40: 5-13, 16-18). International Journal of Dream Research, 9(1), 46-57.

Lv, M. J. (2012). The interpretation of Zhao People dream culture in the pre-Qin Dynasty. Journal of Handan College, 22(2), 3943 (in Chinese).

Meissner, W. W. (1984). Psychoanalysis and Religious Experience. New Haven, Connecticut: Yale University Press.

Pu, S. L. (1916). Strange Stories from a Chinese Studio. H. A. Giles (Ed. \& Trans.). Shanghai: Kelly \& Walsh.

Schredl, M. (2000). The effect of dreams on waking life. Sleep and Hypnosis, 2(3), 120-124.

Schredl, M., Stumbrys, T., \& Erlacher, D. (2016). Dream recall, nightmare frequency, and spirituality. Dreaming, 26(1), 1-9.

Shushan, G. (2006). Greek and Egyptian dreams in two Ptolemaic archives: Individual and cultural layers of meaning. Dreaming, 16(2), 129-142.

Solms, M., \& Moorcroft, W. (1998). The neuropsychology of dreams. Dreaming, 8(1), pp. 41-43.

Walden, D., \& Poch, H. (1998). Psychoanalysis of dreams: Dream theory and its relationship to literature and popular culture: Freud, Bill Joel, Appelfeld, and Abe. Journal of Popular Culture, 32(1), 113-120.

Westerink, H. (2009). A Dark Trace. Sigmund Freud on the Sense of Guilt. Leuven: Leuven University Press.

Wilhelm, R. (trans.). (1967). The I Ching or Book of Changes. Princeton: Princeton University Press.

Wolman, B. B. (1984). Logic of Science in Psychoanalysis. New York, NY: Columbia University Press.

Yin, F., Li, Q., \& Shen, H. Y. (2015). Death dreams from an implicit perspective: A cross-cultural comparison between Tibetan and Han Chinese dreamers. Dreaming, 25(2), 103-117.

Zadra, A., Pilon, M., \& Donderi, D. C. (2006). Variety and intensity of emotions in nightmares and bad dreams. Journal of Nervous and Mental Disease, 194(4), 249-254.

Zheng, B. L., \& Yang, P. (1995). Dunhuang Dream Interpretation. Lanzhou: Gansu Culture 